\title{
Drying Kinetics and Rehydration Characteristics of Convective Hot-Air Dried White Button Mushroom Slices
}

\author{
İbrahim Doymaz \\ Department of Chemical Engineering, Yildiz Technical University, Esenler, 34210 Istanbul, Turkey \\ Correspondence should be addressed to İbrahim Doymaz; doymaz@yildiz.edu.tr
}

Received 7 March 2014; Revised 20 May 2014; Accepted 20 May 2014; Published 5 June 2014

Academic Editor: Albert Demonceau

Copyright (C) 2014 İbrahim Doymaz. This is an open access article distributed under the Creative Commons Attribution License, which permits unrestricted use, distribution, and reproduction in any medium, provided the original work is properly cited.

\begin{abstract}
The effect of pretreatment $\left(0.5 \%\right.$ citric acid solution) and drying air temperature $\left(40,50,60\right.$, and $\left.70^{\circ} \mathrm{C}\right)$ on drying characteristics of button mushroom slices was investigated in a cabinet dryer. The experimental results show that the drying temperature and pretreatment have significant effects on the moisture removal from mushroom. In addition, rehydration ratio of pretreated samples was higher than that of control ones. Four kinds of classical model were used to obtain moisture data and the logarithmic model was the best for representation of mushroom drying. The values of effective moisture diffusivity were found to range between $1.70 \times 10^{-10}$ and $7.12 \times 10^{-10} \mathrm{~m}^{2} / \mathrm{s}$ over the temperature range studied. The activation energy was found to be 35.04 and $37.21 \mathrm{~kJ} / \mathrm{mol}$ for control and pretreated samples, respectively.
\end{abstract}

\section{Introduction}

Mushrooms have been used throughout the world for many centuries. They are considered to be good sources of crude proteins, carbohydrates, lipids, and dietary fibre. Moreover, they are excellent sources of thiamine, riboflavin, nicotinic acid, biotin, and ascorbic acid [1]. Out of 38,000 known mushroom varieties, the most popular are Agaricus bisporus (white button mushroom), Lentinus edodes (Shitake or Japanese mushroom), Pleurotus species (oyster mushroom), Volvariella volvacea (paddy straw mushroom), Flammulina velutipes (winter mushroom), and the Auricularia polytricha (Jew's ear mushroom) [2]. The button mushroom (Agaricus bisporus) is the most widely planted and consumed mushroom throughout the world and it contributes to about $40 \%$ of the world production mushroom [3]. Due to their high moisture content, mushrooms are highly perishable as they start deterioration soon after harvest, with a shelf life of 1-2 days at room temperature [4]. Among the various methods employed for preservation, canning is the most frequently adopted method in commercial scale. Mushroom can be processed in many other methods to extend their self-life such as pickling and drying [2]. Dried mushrooms are used as an important ingredient in several food formulations including instant soups, pasta salads, snack seasonings, stuffing, casseroles, and meat and rice disks [5].

Drying is one of the methods of food preservation. The main attribute of this method is the decrease in the water activity in the product by decreasing its water content, inhibiting the development of microorganisms, and decreasing spoilage reactions, thus prolonging the shelf life of the product [6]. It also provides an extension of shelf life, lighter weight for transportation, and less space for storage. Drying combined with some pretreatments appears to be a cost effective method of preservation. Pretreatments of some agricultural foods prior to drying have been reported to help reduce some of undesired changes such as colour and textural changes. Also, they reduce drying time by relaxing tissue structure and yield a good quality to dried product. Potassium and sodium hydroxide, potassium carbonate, potassium metabisulphate, methyl and ethyl ester emulsions, and citric and ascorbic acids are the most common and commercially used pretreatments [7-9].

The most relevant aspects of drying technology are the mathematical modeling of the process and the experimental setup. The modeling is basically based on the design of 
a set of equations to describe the system as accurately as possible. Drying characteristics of the particular products being dried and mathematical models are needed in the design, construction, and operation of drying systems [10]. Mathematical models of the drying processes are used for designing new or improving existing drying systems or even for the control of the drying process. Many mathematical models have been proposed to describe the drying process; of them, thin-layer drying models have been widely in use. These models can be categorized as theoretical, semitheoretical, and empirical models. Recently, there have been many researches on the mathematical modelling and experimental studies of the drying characteristics of various vegetables and fruits, such as grape [8], sweet potato [11], mango [12], and others. There are several studies in the literature related to the drying characteristics of mushroom. For example, Çelen et al. [13] investigated drying characteristics of mushrooms at different air temperatures of $40,45,50$, and $60^{\circ} \mathrm{C}$ and different slice thickness of 2,4 , and $6 \mathrm{~mm}$. The experimental results show that the drying temperature has a significant effect on the moisture removal from mushrooms. Walde et al. [2] found that the dehydration characteristics of mushroom were also examined by using different pretreatments (blanching, followed by soaking in potassium metabisulphate, fermented whey, and curds) and drying systems (hot-air cabinet dryer, fluidized bed dryer, vacuum dryer, and microwave oven). The results show that microwave drying may not be a suitable method for the drying of mushrooms. Xanthopoulos et al. [14] investigated the effect of drying air temperature $\left(50-65^{\circ} \mathrm{C}\right)$ and air velocity $(1-5 \mathrm{~m} / \mathrm{s})$ on drying kinetics of mushroom slices. The statistical analysis concluded that the best model in terms of fitting performance was the logarithmic model. However, pretreatment such as citric acid solution on drying kinetics, effective moisture diffusivity, and activation energy of mushroom slices has not yet been reported. The objectives of this study were to study the effects of pretreatment on the drying kinetics and the rehydration ratio, fit experimental data to four thin-layer drying models, and compute effective moisture diffusivity and activation energy values using mushroom slices.

\section{Material and Methods}

2.1. Sample Preparation. Fresh button mushrooms (Agaricus bisporus) were obtained from a local supermarket in Istanbul and kept in a refrigerator $\left(4^{\circ} \mathrm{C}\right)$ prior to the experiments. For samples preparation, the mushrooms were washed with tap water and dripped. Then, the samples were separated from the stems and vertically cut into four pieces for drying in order to increase the surface area and divided into two lots before use. One lot of mushroom slices was pretreated with solution of citric acid $(0.5 \%)$ at $20^{\circ} \mathrm{C}$ for $3 \mathrm{~min}$ (citric acid). The other lot was untreated (control).

The initial moisture content of mushroom slices was determined by using the oven method at $110^{\circ} \mathrm{C}$ for $24 \mathrm{~h}$. Triplicate samples were used for the determination of moisture content and the average values were reported as $10.3122 \mathrm{~kg}$ water/kg dry matter (d.b.).
2.2. Drying Apparatus. Drying experiments were carried out using a cabinet dryer (APV \& PASILAC Limited of Carlisle, Cumbria, UK), described previously by Doymaz [15]. It basically consists of a centrifugal fan to supply the air flow, an electric heater, an air filter, and an electronic proportional controller. The air velocity above the product was measured using an anemometer (AM-4201, Lutron, Taipei, Taiwan) with an accuracy $0.1 \mathrm{~m} / \mathrm{s}$. The air is heated to the desired temperature in the heating unit and channeled to the drying chamber. The air temperature in the dryer was regulated to $\pm 1^{\circ} \mathrm{C}$ using a temperature controller. The samples were dried in a perforated tray (radius: $29 \mathrm{~cm}$ and height: $7 \mathrm{~cm}$ ). Weight loss of samples was recorded by using a digital balance (model BB3000, Mettler-Toledo AG, Grefensee, Switzerland), which has $0-3000 \mathrm{~g}$ measurement range with reading accuracy of $0.1 \mathrm{~g}$.

2.3. Experimental. The cabinet dryer was started about $30 \mathrm{~min}$ before drying experiments to achieve steady-state conditions before each drying run. Then, the mushroom slices weighing about $50 \pm 1 \mathrm{~g}$ were spread to thickness $1 \mathrm{~cm}$ on the tray. The drying experiments were conducted at 40, 50, 60, and $70^{\circ} \mathrm{C}$ air temperatures and constant air velocity of $2 \mathrm{~m} / \mathrm{s}$. Air flowed perpendicular to drying surfaces of the samples. Initial weight of the tray and sample was noted. During drying process, the tray was taken out at 15-min interval and weighed using a digital electronic balance. Drying was stopped when the moisture content of samples was approximately $0.085 \mathrm{~kg}$ water $/ \mathrm{kg}$ dry matter. The dried product was cooled and packaged in low-density polyethylene bags and then heat-sealed. The drying experiments were carried out in triplicate. Drying data were analyzed using two-way analysis of variance at $P<0.05$.

2.4. Rehydration Experiments. Rehydration experiments for dried samples at $40^{\circ} \mathrm{C}$ were carried out in distilled water bath at temperature of 25 and $50^{\circ} \mathrm{C}\left( \pm 1^{\circ} \mathrm{C}\right)$. Approximately $1 \mathrm{~g}$ of dried samples was added to $400 \mathrm{~mL}$ distilled water, in a $500 \mathrm{~mL}$ beaker. The sample was withdrawn from the liquid every $20 \mathrm{~min}$, and excess water was carefully removed by blotting on a tissue paper, before weighing. The actual rehydration duration was $240 \mathrm{~min}$. Weights of dried and rehydrated samples were measured using an electronic digital balance (Precisa, model XB220A, Precisa Instruments AG, Dietikon, Switzerland) having a sensitivity of $0.001 \mathrm{~g}$. The rehydration ratio (RR) was calculated by the following equation:

$$
\mathrm{RR}=\frac{W_{r}}{W_{d}},
$$

where $W_{r}$ is the weight of moisture $(\mathrm{kg})$ and $W_{d}$ is the weight of dry matter $(\mathrm{kg})$.

2.5. Mathematical Modeling. Moisture content was calculated using the following equation:

$$
M=\frac{\left(W_{0}-W\right)-W_{1}}{W_{1}},
$$


TABLE 1: Mathematical models given by various authors for drying curves.

\begin{tabular}{lcc}
\hline Model name & Model & Reference \\
\hline Lewis & $\mathrm{MR}=\exp (-k t)$ & Roberts et al. [16] \\
Henderson and Pabis & $\mathrm{MR}=a \exp (-k t)$ & Ghodake et al. [17] \\
Logarithmic & $\mathrm{MR}=a \exp (-k t)+c$ & Xanthopoulos \\
Page & $\mathrm{MR}=\exp \left(-k t^{n}\right)$ & et al. [14] \\
\hline
\end{tabular}

where $M$ is the moisture content ( $\mathrm{kg}$ water $/ \mathrm{kg}$ dry matter), $W_{0}$ is initial weight of sample $(\mathrm{kg}), W$ is the amount of evaporated moisture $(\mathrm{kg})$, and $W_{1}$ is dry matter content of sample (kg). Experimental data from the different drying runs were expressed as moisture ratio versus drying time and drying rate versus moisture content.

Data derived from drying of mushroom slices were fitted to four thin-layer drying models (Table 1). The moisture ratio (MR) of the samples is defined according to the following equation:

$$
\mathrm{MR}=\frac{M_{t}-M_{e}}{M_{0}-M_{e}},
$$

where $M_{t}, M_{0}$, and $M_{e}$ are moisture contents at any time, the initial moisture content, and the equilibrium moisture content ( $\mathrm{kg}$ water $/ \mathrm{kg}$ dry matter), respectively, and $t$ is the drying time ( $\mathrm{min})$. The value of $M_{e}$ is relatively small for long drying times, compared to values of $M_{t}$ and $M_{0}$, so the equation can be simplified to $[12,19]$

$$
\mathrm{MR}=\frac{M_{t}}{M_{0}} .
$$

The drying rate (DR) of mushroom slices was calculated using the following equation:

$$
\mathrm{DR}=\frac{M_{t}-M_{t+\Delta t}}{\Delta t},
$$

where $M_{t+\Delta t}$ is moisture content at $t+\Delta t$ ( $\mathrm{kg}$ water $/ \mathrm{kg}$ dry matter) and $t$ is time (min).

2.6. Statistical Analysis. Data were analyzed using Statistica 6.0 (Statsoft Inc., Tulsa, OK) software package. Model parameters were estimated using a nonlinear regression procedure based on the Levenberg-Marquardt algorithm. The fitting quality of the experimental data to all models was evaluated using the coefficient of determination $\left(R^{2}\right)$, the reduced chisquare $\left(\chi^{2}\right)$, and the root mean square error (RMSE). These parameters were calculated from the following formulas:

$$
\begin{aligned}
\chi^{2} & =\frac{\sum_{i=1}^{N}\left(\mathrm{MR}_{\mathrm{exp}, i}-\mathrm{MR}_{\mathrm{pre}, i}\right)^{2}}{N-z}, \\
\mathrm{RMSE} & =\left[\frac{1}{N} \sum_{i=1}^{N}\left(\mathrm{MR}_{\mathrm{pre}, i}-\mathrm{MR}_{\mathrm{exp}, i}\right)^{2}\right]^{1 / 2},
\end{aligned}
$$

where $\mathrm{MR}_{\text {exp }, i}$ and $\mathrm{MR}_{\text {pre }, i}$ are experimental and predicted dimensionless moisture ratios, respectively, $N$ is the number of observations, and $z$ is the number of constants. The best model describing the drying kinetics of samples was chosen as the model with the lowest $\chi^{2}$ and RMSE values and the highest $R^{2}$ value $[12,20]$.

2.7. Calculation of Moisture Diffusivity. Fick's second law can be derived as follows:

$$
\frac{\partial M}{\partial t}=\Delta\left[D_{\mathrm{eff}}(\Delta M)\right]
$$

where $M$ is the local moisture content ( $\mathrm{kg}$ water $/ \mathrm{kg}$ dry matter), $t$ is the time (s), and $D_{\text {eff }}$ is the effective moisture diffusivity $\left(\mathrm{m}^{2} / \mathrm{s}\right)$. Equation (7) can be used to determine the moisture ratio in terms of infinite series by giving the analytical solutions for various regularly shaped bodies, such as rectangular, cylindrical, and spherical shapes, with the appropriate initial and boundary conditions shown as followed:

$$
\begin{gathered}
t=0, \quad 0<x<L, \quad M=M_{0}, \\
t>0, \quad x=0, \quad \frac{\partial M}{\partial t}=0, \\
t>0, \quad x=L, \quad M=M_{0} .
\end{gathered}
$$

The present case was considered of slab geometry, and then the first boundary condition states that moisture is initially uniformly distributed throughout the sample. The second implies that the mass transfer is symmetric with respect to the centre of the slab. The third condition states that the surface moisture content of the samples instantaneously reaches equilibrium with the conditions of surroundings air [21].

The solution of Fickian diffusion equation (7) in such conditions for an infinite slab, assuming unidimensional moisture movement volume change, constant temperature, and diffusivity coefficients, and negligible external resistance [22] can be as follows:

$$
\mathrm{MR}=\frac{8}{\pi^{2}} \sum_{n=0}^{\infty} \frac{1}{(2 n+1)^{2}} \exp \left(-\frac{(2 n+1)^{2} \pi^{2} D_{\mathrm{eff}} t}{4 L^{2}}\right),
$$

where $D_{\text {eff }}$ is the effective moisture diffusivity $\left(\mathrm{m}^{2} / \mathrm{s}\right), L$ is the half-thickness of the slab (m), and $n$ is the positive integer. For long drying times, equation (9) simplifies to a limiting form of the diffusion equation as follows:

$$
\mathrm{MR}=\frac{8}{\pi^{2}} \exp \left(-\frac{\pi^{2} D_{\mathrm{eff}} t}{4 L^{2}}\right)
$$

This could be further converted into a straight-line equation as

$$
\ln (\mathrm{MR})=\ln \left(\frac{8}{\pi^{2}}\right)-\frac{\pi^{2} D_{\mathrm{eff}}}{4 L^{2}} .
$$

The effective moisture diffusivity was calculated from a slope of a straight line by plotting experimental drying data in terms of $\ln (\mathrm{MR})$ versus drying time. 


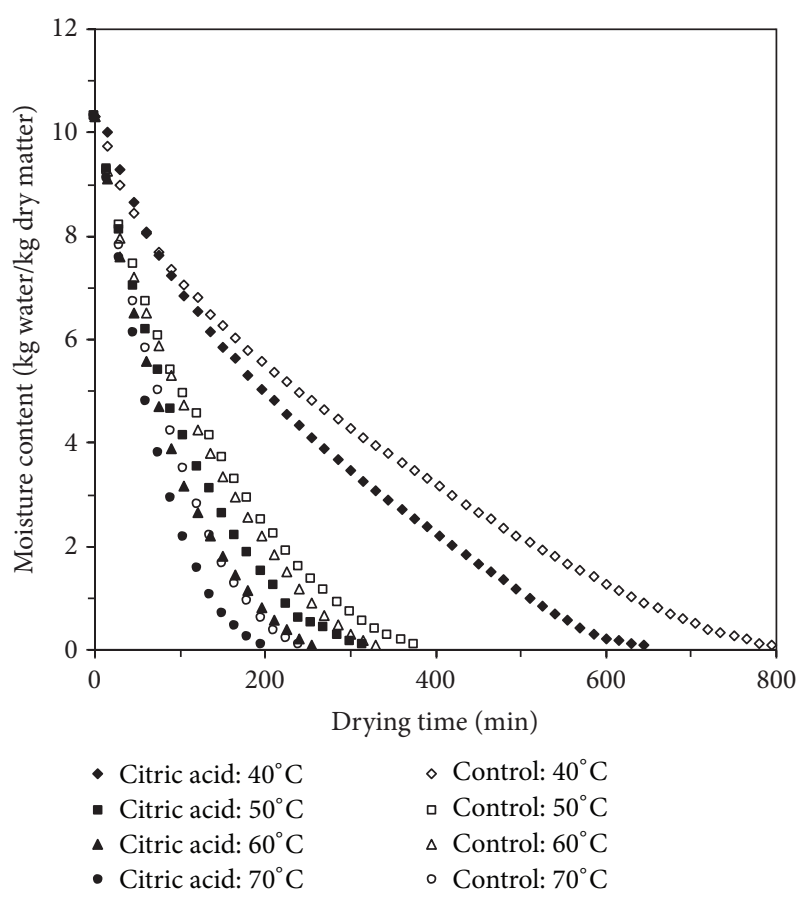

FIGURE 1: Drying curves of mushroom slices with a citric acid solution or without treatment at different temperatures.

2.8. Calculation of the Activation Energy. Effective moisture diffusivity can be related with temperature by Arrhenius expression like

$$
D_{\mathrm{eff}}=D_{0} \exp \left(-\frac{E_{a}}{R(T+273.15)}\right)
$$

where $D_{0}$ is a constant in the Arrhenius equation $\left(\mathrm{m}^{2} / \mathrm{s}\right), E_{a}$ is the activation energy $(\mathrm{kJ} / \mathrm{mol}), T$ is temperature of air $\left({ }^{\circ} \mathrm{C}\right)$, and $R$ is the universal gas constant $(\mathrm{kJ} / \mathrm{mol} \mathrm{K})$. Equation (12) can be rearranged into form of

$$
\ln \left(D_{\mathrm{eff}}\right)=\ln \left(D_{0}\right)-\frac{E_{a}}{R(T+273.15)}
$$

\section{Results and Discussion}

3.1. Drying Curves. Curves of moisture content versus drying time for pretreated and control samples are presented in Figure 1. It is apparent that moisture content and drying rate decrease continuously with the drying time. Figure 2 shows the changes in the drying rate as a function of moisture content at $40,50,60$, and $70^{\circ} \mathrm{C}$. As shown in these figures, the falling-rate period was mostly observed in both mushroom samples at different drying temperature. It means that the physical mechanism governing moisture movement in the samples is dominated by the diffusion of water vapor or bound water through the dry tissue to the drying air at a rate slower than the evaporation rate from the surface [23]. Results are in good agreement with the earlier observations of drying of various products $[4,14,24,25]$.

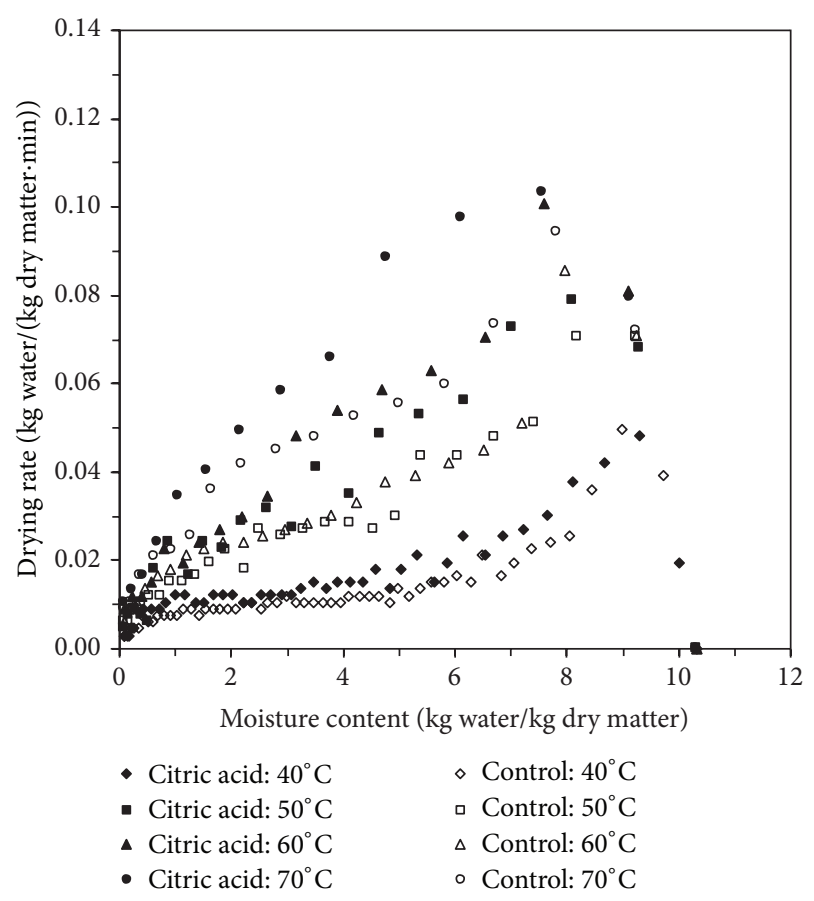

FIGURE 2: Drying rate versus moisture content of mushroom slices at different temperatures.

3.2. Influence of Pretreatment. Pretreatment is an important parameter that affects drying time (Figure 1). Samples dipped in a citric acid solution prior to drying had a shorter drying time compared to control samples. They reach a final water content $(0.085 \pm 0.05 \mathrm{~kg}$ water $/ \mathrm{kg}$ dry matter $)$ for control samples; $795 \mathrm{~min}$ of drying at $40^{\circ} \mathrm{C}$ were needed, while mushroom slices treated with a citric acid solution reached this water content after $660 \mathrm{~min}$. The difference in drying times was close to $16.98 \%$. These results show that citric acid solution contributed to increasing the permeability of the cell membranes of mushroom slices, leading to an increase in moisture diffusivity. Similar trends were observed at drying temperatures of 50,60 , and $70^{\circ} \mathrm{C}$. The observed treatment effects on drying characteristics have also been reported in previous investigations of different agricultural products [9, 26-28].

3.3. Fitting of Drying Curves. The moisture content data observed by hot-air drying experiments are converted into the moisture ratio (3) and fitted to the four models listed in Table 1. Nonlinear regression was used to obtain each parameter value of every model. The best model describing the thin-layer drying characteristics of mushroom slices was chosen as the one with the highest $R^{2}$ values and the lowest $\chi^{2}$ and RMSE values. Statistical results from models are summarised in Table 2. The results from Table 2, the statistical parameter estimations showed that $R^{2}, \chi^{2}$, and RMSE values were ranged from 0.9771 to $0.9995,0.000049$ to 0.002553 , and 0.018324 to 0.221051 , respectively. The logarithmic model was found the best for describing the drying kinetics of mushroom slices with $R^{2}, \chi^{2}$, and RMSE ranging between 0.9961 
TABLE 2: Curve fitting criteria for the various mathematical models and parameters for mushroom slices at different temperatures.

\begin{tabular}{|c|c|c|c|c|c|}
\hline Code & Temperature $\left({ }^{\circ} \mathrm{C}\right)$ & Model & $R^{2}$ & $\chi^{2}$ & RMSE \\
\hline \multirow{16}{*}{ Citric acid } & \multirow{4}{*}{40} & Lewis & 0.9844 & 0.001249 & 0.181546 \\
\hline & & Henderson and Pabis & 0.9845 & 0.001194 & 0.182420 \\
\hline & & Logarithmic & 0.9973 & 0.000224 & 0.080368 \\
\hline & & Page & 0.9889 & 0.000908 & 0.167929 \\
\hline & \multirow{5}{*}{50} & Lewis & 0.9908 & 0.000822 & 0.113490 \\
\hline & & Henderson and Pabis & 0.9915 & 0.000794 & 0.112049 \\
\hline & & Logarithmic & 0.9993 & 0.000060 & 0.026051 \\
\hline & & Page & 0.9956 & 0.000411 & 0.070580 \\
\hline & & Lewis & 0.9914 & 0.000812 & 0.097675 \\
\hline & \multirow{3}{*}{60} & Henderson and Pabis & 0.9935 & 0.000650 & 0.084503 \\
\hline & & Logarithmic & 0.9995 & 0.000049 & 0.018324 \\
\hline & & Page & 0.9981 & 0.000185 & 0.044422 \\
\hline & \multirow{4}{*}{70} & Lewis & 0.9771 & 0.002553 & 0.157871 \\
\hline & & Henderson and Pabis & 0.9837 & 0.001961 & 0.136013 \\
\hline & & Logarithmic & 0.9966 & 0.000444 & 0.058682 \\
\hline & & Page & 0.9991 & 0.000103 & 0.029955 \\
\hline \multirow{16}{*}{ Control } & \multirow{4}{*}{40} & Lewis & 0.9825 & 0.001210 & 0.213416 \\
\hline & & Henderson and Pabis & 0.9830 & 0.001233 & 0.213416 \\
\hline & & Logarithmic & 0.9961 & 0.000285 & 0.090161 \\
\hline & & Page & 0.9828 & 0.001250 & 0.221051 \\
\hline & \multirow{5}{*}{50} & Lewis & 0.9901 & 0.000841 & 0.119178 \\
\hline & & Henderson and Pabis & 0.9906 & 0.000830 & 0.119774 \\
\hline & & Logarithmic & 0.9991 & 0.000081 & 0.036355 \\
\hline & & Page & 0.9936 & 0.000561 & 0.101358 \\
\hline & & Lewis & 0.9835 & 0.001438 & 0.161877 \\
\hline & \multirow{3}{*}{60} & Henderson and Pabis & 0.9839 & 0.001469 & 0.162814 \\
\hline & & Logarithmic & 0.9974 & 0.000249 & 0.058673 \\
\hline & & Page & 0.9893 & 0.000978 & 0.119158 \\
\hline & \multirow{4}{*}{70} & Lewis & 0.9807 & 0.001941 & 0.156257 \\
\hline & & Henderson and Pabis & 0.9841 & 0.001703 & 0.147527 \\
\hline & & Logarithmic & 0.9985 & 0.000169 & 0.040552 \\
\hline & & Page & 0.9959 & 0.000432 & 0.063337 \\
\hline
\end{tabular}

and $0.9995,0.000049$ and $0.000444,0.018324$ and 0.090161, respectively. Figure 3 compares experimental data with those fitted data from the logarithmic model for mushroom slices at different temperatures. It can be seen that there was a very good agreement between the experimental and predicted moisture ratio values, which are closely banding around at a $45^{\circ}$ straight line.

3.4. Effective Moisture Diffusivity. The determined values of the effective moisture diffusivity are shown in Figure 4 and were found to range between $1.70 \times 10^{-10} \mathrm{~m}^{2} / \mathrm{s}$ and $7.12 \times 10^{-10} \mathrm{~m}^{2} / \mathrm{s}$. As expected, effective moisture diffusivity increased with increase in drying temperature; it was also observed that the effective moisture diffusivity values were higher for pretreated samples as compared to control samples (Figure 4). The pretreatment solution has probably affected the internal mass transfer during drying. The values of $D_{\text {eff }}$ obtained from this study lie within in general range
$10^{-12}$ to $10^{-8} \mathrm{~m}^{2} / \mathrm{s}$ for drying of food materials [29]. Similar observations have been reported by other researchers $[4,30]$.

3.5. Activation Energy. The activation energy was calculated by plotting $\ln \left(D_{\text {eff }}\right)$ versus the reciprocal of the temperature $(1 /(T+273.15))$ and presented in Figure 5. Equations (14) and (15) show the effect of temperature on $D_{\text {eff }}$ of the control and pretreated samples with following coefficients:

control:

$$
D_{\text {eff }}=1.264 \times 10^{-4} \exp \left(-\frac{4215.5}{(T+273.15)}\right) \quad\left(R^{2}: 0.9677\right)
$$

citric acid:

$$
D_{\text {eff }}=3.533 \times 10^{-4} \exp \left(-\frac{4475.6}{(T+273.15)}\right) \quad\left(R^{2}: 0.9813\right) \text {. }
$$




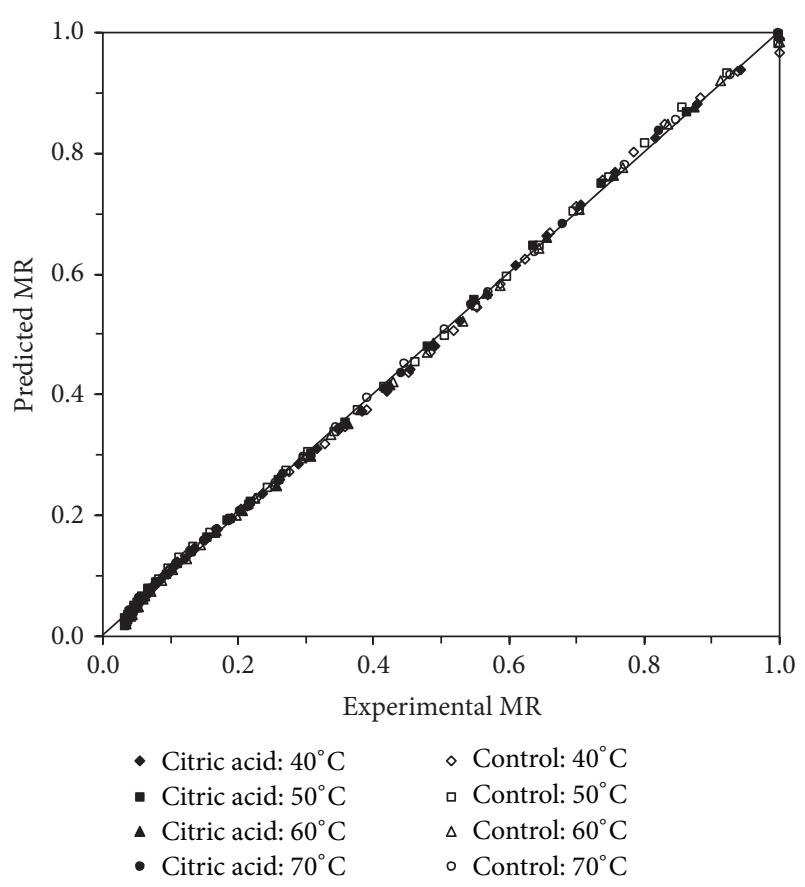

FIGURE 3: Comparison of experimental and predicted moisture ratio values using logarithmic model.

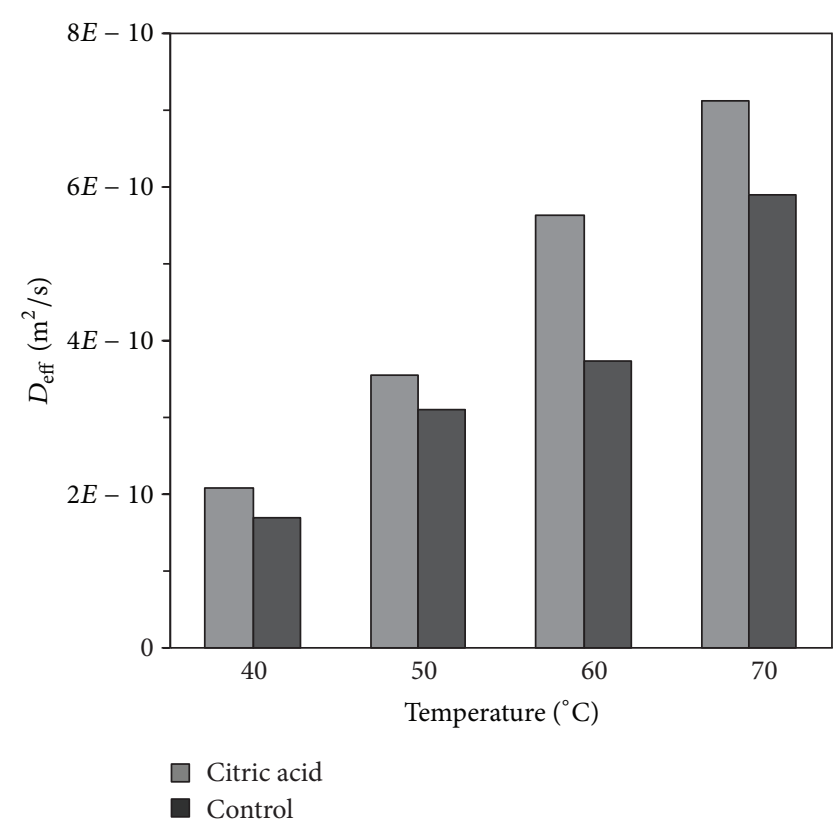

FIGURE 4: Variation of effective moisture diffusivity with drying air temperature.

The activation energy values were found to be 35.04 and $37.21 \mathrm{~kJ} / \mathrm{mol}$ for control and pretreated samples, respectively. The values of activation energy lie within the general range of $12.7-110 \mathrm{~kJ} / \mathrm{mol}$ for food materials [29].

3.6. Rehydration Characteristics. Rehydration is an important quality attribute for dried products. The rehydration

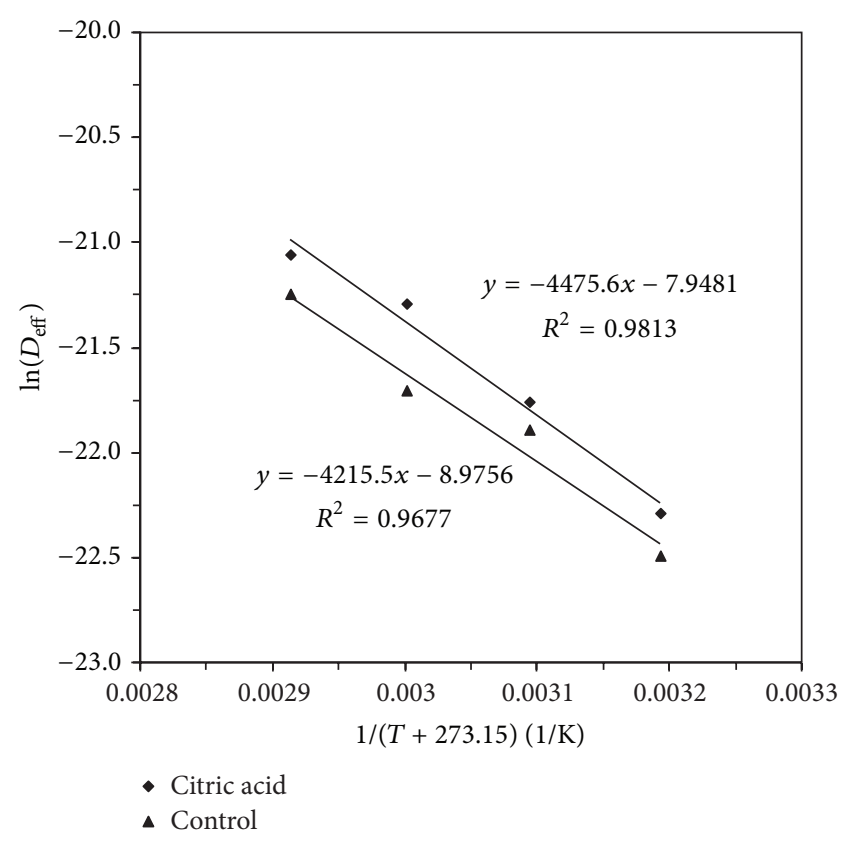

FIGURE 5: Arrhenius-type relationship between effective moisture diffusivity and reciprocal absolute temperature.

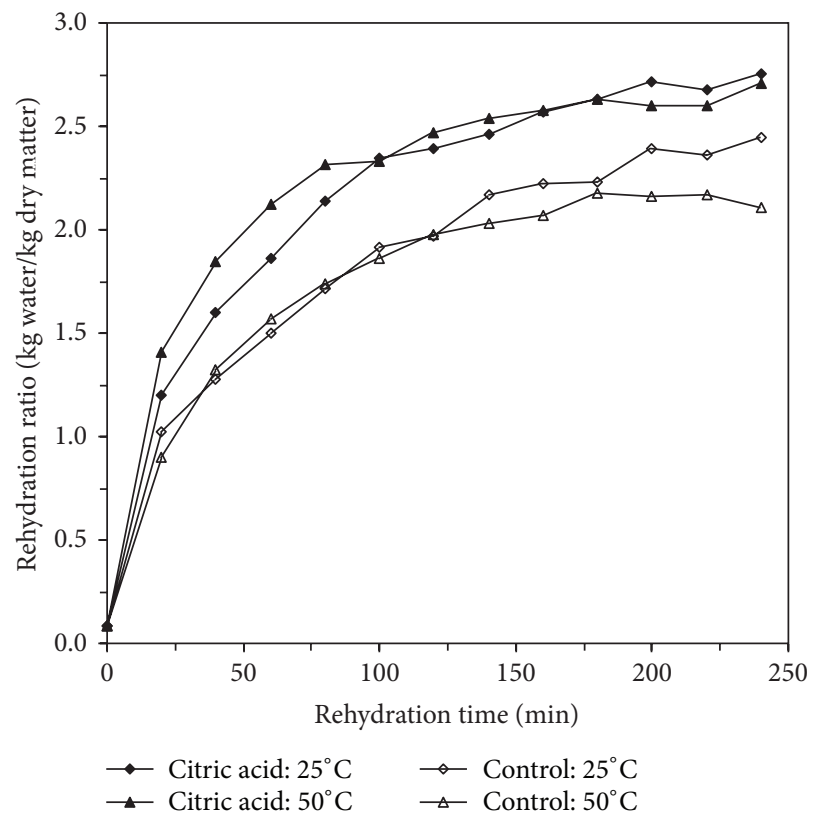

FIGURE 6: Rehydration ratio versus time at rehydration temperatures of 25 and $50^{\circ} \mathrm{C}$ for mushroom slices dried at $40^{\circ} \mathrm{C}$.

characteristics indicate the physical and chemical changes during drying as influenced by processing conditions, pretreatment, and composition of samples [31]. The values of rehydration ratio at different rehydration temperatures, calculated from (1), are shown in Figure 6. It was observed that the rehydration ratio of pretreated samples resulted in the highest rehydration, compared to the control samples. 


\section{Conclusions}

The effect of pretreatment on drying of mushroom slices using hot air was studied. Drying rate and rehydration ratio of pretreated samples increased compared to control samples. Drying process occurred in the falling-rate period. To explain the drying kinetics of mushroom slices, four thin-layer drying models were compared according to their $R^{2}, \chi^{2}$, and RMSE values. Logarithmic model has shown to be the best fit to the experimental data. The values of effective moisture diffusivity were found to range between $1.70 \times 10^{-10}$ and $7.12 \times 10^{-10} \mathrm{~m}^{2} / \mathrm{s}$. The activation energy was found to be 35.04 and $37.21 \mathrm{~kJ} / \mathrm{mol}$ for control and pretreated samples, respectively.

\section{Conflict of Interests}

The author declares that there is no conflict of interests regarding the publication of this paper.

\section{References}

[1] H. Gençcelep, "The effect of using dried mushroom (Agaricus bisporus) on lipid oxidation and color properties of sucuk," Journal of Food Biochemistry, vol. 36, no. 5, pp. 587-594, 2012.

[2] S. G. Walde, V. Velu, T. Jyothirmayi, and R. G. Math, "Effects of pretreatments and drying methods on dehydration of mushroom," Journal of Food Engineering, vol. 74, no. 1, pp. 108-115, 2006.

[3] S. K. Giri and S. Prasad, "Drying kinetics and rehydration characteristics of microwave-vacuum and convective hot-air dried mushrooms," Journal of Food Engineering, vol. 78, no. 2, pp. 512-521, 2007.

[4] L. E. Kurozawa, P. M. Azoubel, F. E. X. Murr, and K. J. Park, "Drying kinetic of fresh and osmotically dehydrated mushroom (Agaricus blazei)," Journal of Food Process Engineering, vol. 35, no. 2, pp. 295-313, 2012.

[5] J. Raj, M. I. A. Ansari, P. Rai, and G. Prasad, "Optimization of drying conditions of button mushroom (Agaricusbisporous)," Journal of Research, vol. 25, pp. 36-40, 2013.

[6] P. S. Pisalkar, N. K. Jain, P. B. Pathare, R. P. Murumkar, and V. A. Revaskar, "Osmotic dehydration of aloe vera cubes and selection of suitable drying model," International Food Research Journal, vol. 21, pp. 373-378, 2014.

[7] S. Tarhan, G. Ergunes, and O. F. Taser, "Selection of chemical and thermal pretreatment combination to reduce the dehydration time of sour cherry (Prunus cerasus L.)," Journal of Food Process Engineering, vol. 29, no. 6, pp. 651-663, 2006.

[8] G. Bingol, Z. Pan, J. S. Roberts, Y. Onur Devres, and M. O. Balaban, "Mathematical modeling of microwave-assisted convective heating and drying of grapes," International Journal of Agricultural and Biological Engineering, vol. 1, no. 2, pp. 4654, 2008.

[9] I. Doymaz, "Effect of citric acid and blanching pre-treatments on drying and rehydration of Amasya red apples," Food and Bioproducts Processing, vol. 88, no. 2-3, pp. 124-132, 2010.

[10] C. A. Ruiz, C. Francisco, L. R. Fernando, and R. Aida, "Thin layer drying behavior of industrial tomato bye-products in a convective dryer at low temperatures," Research Journal of Biotechnology, vol. 8, no. 2, pp. 50-60, 2013.

[11] S. Singh, C. S. Raina, A. S. Bawa, and D. C. Saxena, "Effect of pretreatments on drying and rehydration kinetics and color of sweet potato slices," Drying Technology, vol. 24, no. 11, pp. 1487$1494,2006$.

[12] A. O. Dissa, D. J. Bathiebo, H. Desmorieux, O. Coulibaly, and J. Koulidiati, "Experimental characterisation and modelling of thin layer direct solar drying of Amelie and Brooks mangoes," Energy, vol. 36, no. 5, pp. 2517-2527, 2011.

[13] S. Çelen, K. Kahveci, U. Akyol, and A. Haksever, "Drying behavior of cultured mushrooms," Journal of Food Processing and Preservation, vol. 34, no. 1, pp. 27-42, 2010.

[14] G. Xanthopoulos, G. Lambrinos, and H. Manolopoulou, "Evaluation of thin-layer models for mushroom (Agaricus bisporus) drying," Drying Technology, vol. 25, no. 9, pp. 1467-1477, 2007.

[15] I. Doymaz, "Effect of pre-treatments using potassium metabisulphide and alkaline ethyl oleate on the drying kinetics of apricots," Biosystems Engineering, vol. 89, no. 3, pp. 281-287, 2004.

[16] J. S. Roberts, D. R. Kidd, and O. Padilla-Zakour, "Drying kinetics of grape seeds," Journal of Food Engineering, vol. 89, no. 4, pp. 460-465, 2008.

[17] H. M. Ghodake, T. K. Goswami, and A. Chakraverty, "Mathematical modeling of withering characteristics of tea leaves," Drying Technology, vol. 24, no. 2, pp. 159-164, 2006.

[18] A. Kaleta, K. Górnicki, R. Winiczenko, and A. Chojnacka, "Evaluation of drying models of apple (var. Ligol) dried in a fluidized bed dryer," Energy Conversion and Management, vol. 67, pp. 179-185, 2013.

[19] A. Balbay and Ö. Şahin, "Microwave drying kinetics of a thinlayer liquorice root," Drying Technology, vol. 30, no. 8, pp. 859864, 2012.

[20] T. Y. Tunde-Akintunde, "Mathematical modeling of sun and solar drying of chilli pepper," Renewable Energy, vol. 36, no. 8, pp. 2139-2145, 2011.

[21] Y. Zhang, H. Chen, and T. Chen, "Drying kinetics of RDX under atmospheric pressure and vacuum conditions," Energy Conversion and Management, vol. 80, pp. 266-275, 2014.

[22] J. Crank, The Mathematics of Diffusion, Oxford University Press, London, UK, 2nd edition, 1975.

[23] W. Duangkamchan, L. Wiset, and N. Poomsa-ad, "Evaluation of drying and moisture sorption characteristics models for Shiitake mushroom (Lentinussquarrosulus Mont.) and Grey Oyster mushroom (Pleurotussajor-caju (fr.) Singer)," Suranaree Journal of Science and Technology, vol. 20, pp. 151-166, 2013.

[24] E. K. Akpinar and Y. Bicer, "Modelling of the drying of eggplants in thin-layers," International Journal of Food Science and Technology, vol. 40, no. 3, pp. 273-281, 2005.

[25] P. S. Kumar, M. Kanwat, and V. K. Choudhary, "Mathematical modeling and thin-layer drying kinetics of bamboo slices on convective tray drying at varying temperature," Journal of Food Processing and Preservation, vol. 37, pp. 914-923, 2013.

[26] B. Hiranvarachat, S. Devahastin, and N. Chiewchan, "Effects of acid pretreatments on some physicochemical properties of carrot undergoing hot air drying," Food and Bioproducts Processing, vol. 89, no. 2, pp. 116-127, 2011.

[27] K. O. Falade and O. J. Solademi, "Modelling of air drying of fresh and blanched sweet potato slices," International Journal of Food Science and Technology, vol. 45, no. 2, pp. 278-288, 2010.

[28] A. Vega-Gálvez, E. Lara, V. Flores, K. Di Scala, and R. LemusMondaca, "Effect of selected pretreatments on convective drying process of blueberries (var. O'neil)," Food and Bioprocess Technology, vol. 5, no. 7, pp. 2797-2804, 2012. 
[29] N. P. Zogzas, Z. B. Maroulis, and D. Marinos-Kouris, "Moisture diffusivity data compilation in foodstuffs," Drying Technology, vol. 14, no. 10, pp. 2225-2253, 1996.

[30] J. H. Lee and H. J. Kim, "Vacuum drying kinetics of Asian white radish (Raphanus sativus L.) slices," Food Science and Technology, vol. 42, no. 1, pp. 180-186, 2009.

[31] H. Feng and J. Tang, "Microwave finish drying of diced apples in a spouted bed," Journal of Food Science, vol. 63, no. 4, pp. 679683, 1998. 

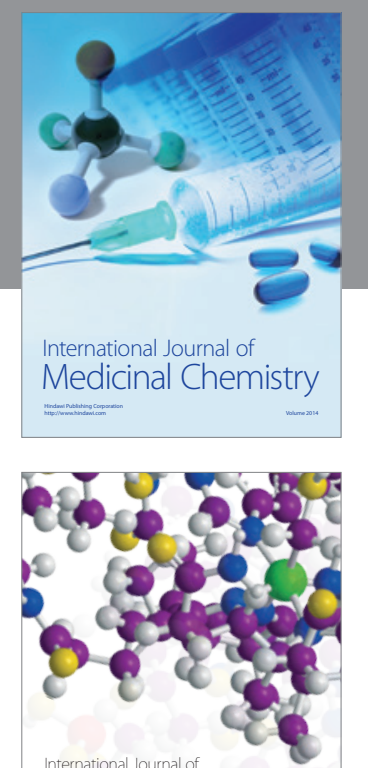

\section{Carbohydrate} Chemistry

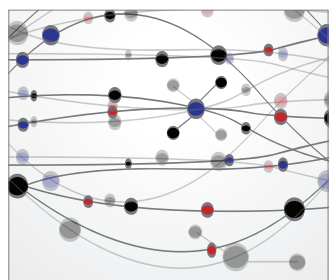

The Scientific World Journal
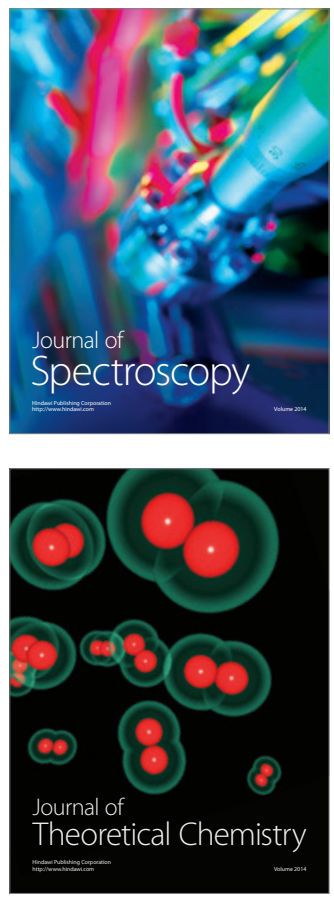
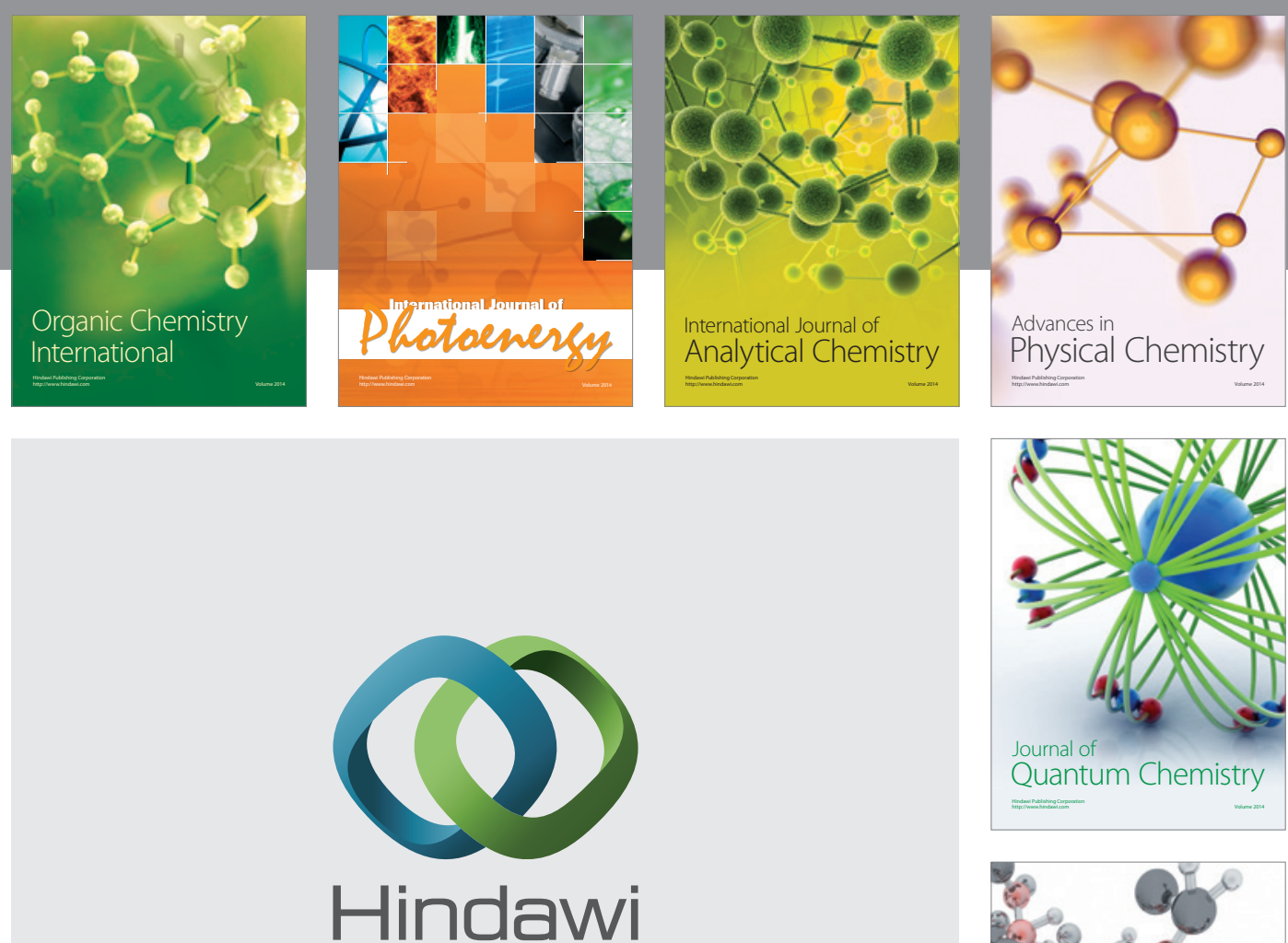

Submit your manuscripts at

http://www.hindawi.com

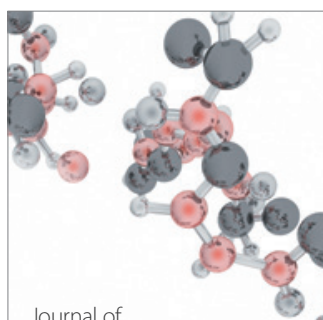

Analytical Methods

in Chemistry

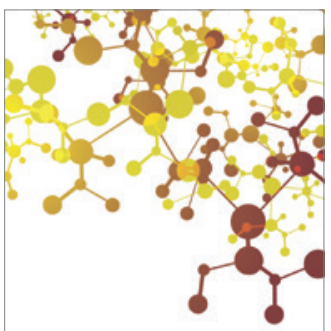

Journal of

Applied Chemistry

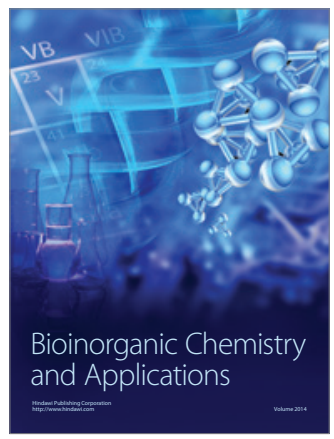

Inorganic Chemistry
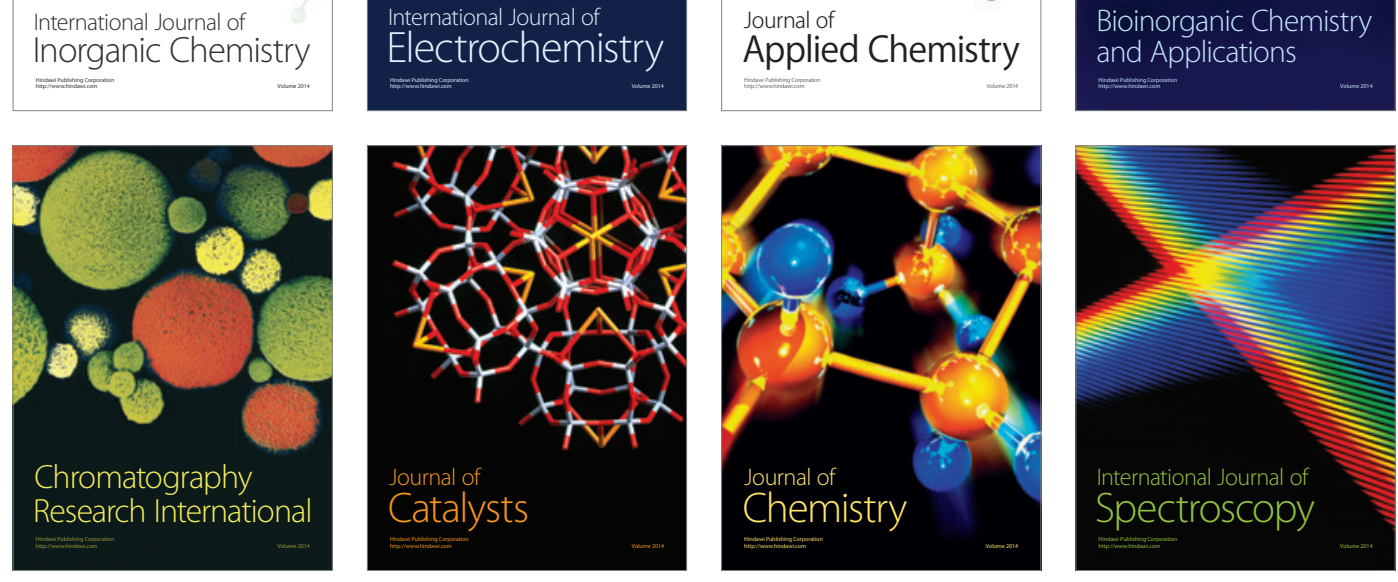